J. Amer. Soc. Hort. Sci. 120(4):661-666. 1995.

\title{
Identifying Pecan Cultivars by Isozymes and Inheritance of Leucine Aminopeptidase
}

\author{
Robert D. Marquard ${ }^{1}$ \\ Texas A\&M Research and Extension Center, 1380 A\&M Circle, El Paso, TX 79927
}

Larry J. Grauke and Tommy E. Thompson

U.S. Dept. of Agriculture-Agricultural Research Service Pecan Breeding Station, P.O. Box 133, Somerville, TX 77879

\author{
Ruth S. Janos \\ Texas A\&M Research and Extension Center, 1380 A\&M Circle, El Paso, TX 79927
}

Additional index words. Carya illinoensis, gel electrophoresis, genetics

\begin{abstract}
More than 170 pecan [Carya illinoensis (Wangenh.) K. Koch] cultivars were evaluated formalate dehydrogenase, phosphoglucose isomerase, phosphoglucomutase, leucine aminopeptidase (LAP), and diaphorase (DIA). Isozymes of LAP were observed in two regions after starch gel electrophoresis. The faster region of activity (Lap-1) was polymorphic and consistently expressed in leaves, wood, and roots. Controlled crosses suggest that Lap-1 is simply inherited and controlled by at least two alleles. DIA was well resolved and storable only from leaf material and produced a complex banding pattern. The ability to differentiate among cultivars by isozymes was good. The 177 cultivars sorted into 72 classes. Forty of the cultivars $(23 \%)$ possessed a unique series of isozyme patterns. Most cultivars (124 of 177) shared common banding patterns with less than four other cultivars. From the inheritance models of four isozymes, some historical pedigrees can be questioned. Most notably,' Western Schley' could not have been parented by 'San Saba' based on the inheritance of Mdh-1 and Lap-1.
\end{abstract}

Isozyme analysis by gel electrophoresis can help validate plant pedigrees, phylogeny, ploidy, and mating systems and help distinguish among named cultivars (Peirce and Brewbaker, 1973). Isozymes typically are simply inherited and largely unaffected by the environment. Pecan is presumed to be a heterogeneous species based on the relatively large native range (Little, 1971; Thompson and Grauke, 1990), observed variability of isozymes, and morphological variability. About 1000 cultivars have been named since the mid- 1800s (Thompson and Young, 1985). Pecan breeding by U.S. Dept. of Agriculture (USDA) scientist's began in the 1930s. Most pecan cultivars are wild selections, or have pedigrees that are incomplete or limited to one or two generations.

The National Plant Germplasm System has established a repository in Brownwood, Texas, to maintain cultivars and valuable clones to preserve genetic diversity of pecan (White et al., 1989). Cultivar identification of questionable clones has largely been based on nut morphology, which can vary with environment. Isozyme analysis provides an objective method to identify cultivars if sufficient isozyme systems are well resolved and polymorphic. Currently, three genes are known that are simply inherited and control polymorphic isozymes in pecan (Marquard, 1987, 1989, 1991). Malate dehydrogenase (Mdh-1) is controlled by four alleles, whereas phosphoglucose isomerase (Pgi-2) and phosphoglucomutase $(P g m-1)$ are each controlled by three alleles. PGI, $\mathrm{MDH}$, and PGM are consistently expressed from various vegetative tissues (Marquard and Skorpenske, 1989). Other polymorphic isozyme systems in pecan include alcohol dehydrogenase, esterase, leucine aminopeptidase (LAP), and diaphorase (DIA) (Marquard, personal observation).

The objectives of this study included an $\underset{*}{\text { evaluation of named }}$

Received for publication 19 Sept. 1994. Accepted for publication 24 Jan. 1995. The cost of publishing this paper was defrayed in part by the payment of page charges. Under postal regulations, this paper therefore must be hereby marked advertisement solely to indicate this fact.

'Current Address: The Holden Arboretum, 9500 Sperry Road, Kirtland, OH 44094. pecan cultivars for five isozyme systems including MDH, PGI, PGM, LAP, and DIA; suggesting the genetic control of observed phenotypic banding differences of LAP; determining the tissue specificity of DIA and LAP; and helping substantiate pedigrees of some cultivars using isozyme systems that are simply inherited.

\section{Materials and Methods}

Resolution of isozyme systems was optimized by using three buffer systems (Marquard and Skorpenske, 1989). Briefly, MDH (EC 1.1.1.37) was evaluated from a morpholine based system $(\mathrm{pH}$ 6.1). PGI (EC 5.3.1.9) and DIA (EC 1.6.4.3.) were evaluated on a Tris-citric acid based gel with a lithium hydroxide-boric acid tray buffer (pH 8.1). PGM (EC 2.7.5.1.) and LAP (EC 3.4.11.1) were separated on a histidine-EDTA gel with a Tris-citric acid tray buffer ( $\mathrm{pH}$ 7.0).

Wood or leaves $(0.5 \mathrm{~g})$ from selected pecan cultivars were homogenized in $6 \mathrm{ml}$ of grinding buffer to which $0.5 \mathrm{~g}$ of polyvinylpolypyrrolidone was added. The grinding buffer was composed of $40 \mathrm{~mm}$ sodium phosphate, $200 \mathrm{~mm}$ sucrose, $1 \mathrm{~mm}$ EDTA, $3 \mathrm{~mm}$ dithiothreitol, $5 \mathrm{~mm}$ ascorbic acid, $3 \mathrm{~mm}$ bisulfite, $6 \mathrm{~mm}$ diethydithiocarbamic acid, 5\% polyvinylpyrrolidone $(\mathrm{mw}=$ 40,000), and 0.1\% $\beta$ - mercaptoethanol (Wendel and Parks, 1982).

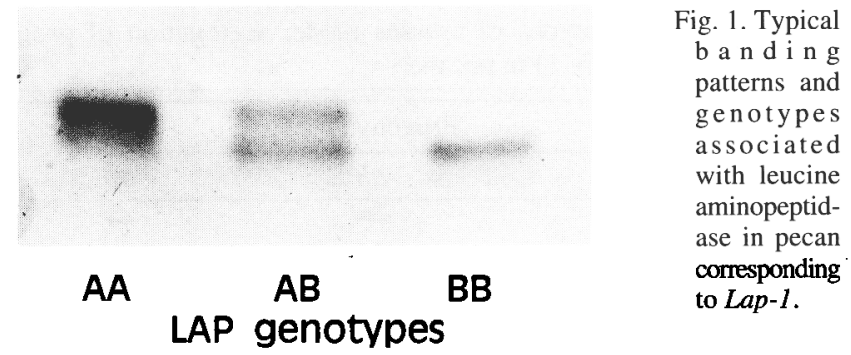




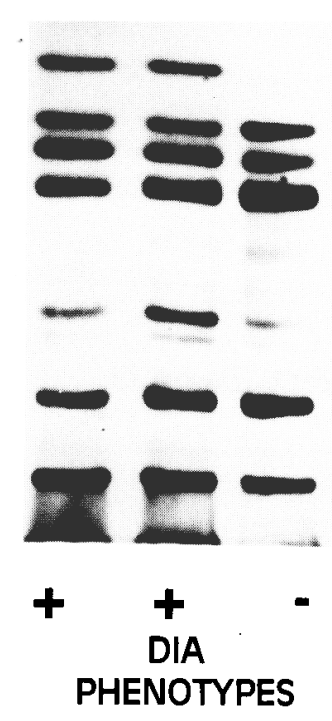

Fig. 2. Typical banding pattern for diaphorase in pecan. The fastest band has a relative mobility of 0.64 . Samples designated (+) have the fastest DIA isozyme whereas the third lane designated (-) lacks this isozyme. Mobility of isozymes is from bottom to top.
Crude protein extracts were $a b-$ sorbed onto sample wicks and loaded onto $12.5 \%$ horizontal starch gels. Standard procedures were used to pour, run, and stain the gels for the enzymes included in this study (Shields et al., 1983; Vallejos, 1983).

To evaluate specificity among vegetative tissues for expression of LAP and DIA, 10 open-pollinated seedlings from 'Choctaw' and 'Riverside' were grown until two or three leaves had fully expanded. Seedlings were uprooted and plant organs were separated into leaves, roots, or stem and individually homogenized as described above and evaluated for LAP and DIA isozymes.

Inheritance of LAP was evaluated from full-sib progeny produced from controlled crosses made in 1987 and 1990. Parents used in controlled crosses included several unnamed selections from the USDA-Agricultural Research Service (ARS) pecan breeding program, 'Riverside', 'Western Schley' and 'Wichita'. All crosses were made in El Paso, TX by R.D. Marquard. Dormant wood or leaf tissue from these progeny were evaluated for phenotypic expression of LAP. Crosses with parents of similiar LAP phenotypes were pooled to provide sufficient numbers for analysis of segregation. Observed segregation ratios were tested for homogeneity by chi-square.

Leaf, or less frequently, twig samples were collected from the most reliable clones representing 177 pecan cultivars. Most plant material was collected from the USDA-ARS pecan breeding facility in Brownwood and can be verified by voucher specimens. Cultivars were characterized for PGM, PGI, MDH, LAP, and DIA. Additional plant material was collected from Louisiana, Georgia, Kansas, and Texas to confirm some of the Brownwood samples or to add other named cultivars.

Cultivars with a known pattern of heterdichogamy (from Thompson and Young, 1985) were also independently analyzed by chi-square against genotypic classes of the four isozyme loci.

\section{Results and Discussion}

Staining for LAP and DIA after starch gel electrophoresis resulted in obvious phenotypic differences among pecan cultivars when leaf tissue was used. Two polymorphic regions of LAP activity were observed on the gels. The faster region (Lap-1) consistently expressed either a double banded or one of two single band phenotypes (Fig. 1). LAP bands of slower mobility were not consistently expressed and phenotypes are not included in this evaluation.

Overall, diaphorase phenotypes from leaf tissue were complex and resulted in up to 10 bands. To simplify the characterization of cultivars from diaphorase, the presence or absence of a single fast band $\left(R_{f}=0.64\right)$ was scored. This band had the fastest mobility of any of the observed diaphorase isozymes, is well resolved, and is well separated from the complex of slower migrating bands (Fig. 2). No attempt was made to explain the genetic control of the fastest migrating DIA band observed in 28 of 177 cultivars. DIA was scored as having (+) or lacking (-) this band (Fig. 2).

The phenotypes of LAP and DIA are diagrammatically shown with the phenotypes and associated genotypes of Mdh-1, Pgi-2,

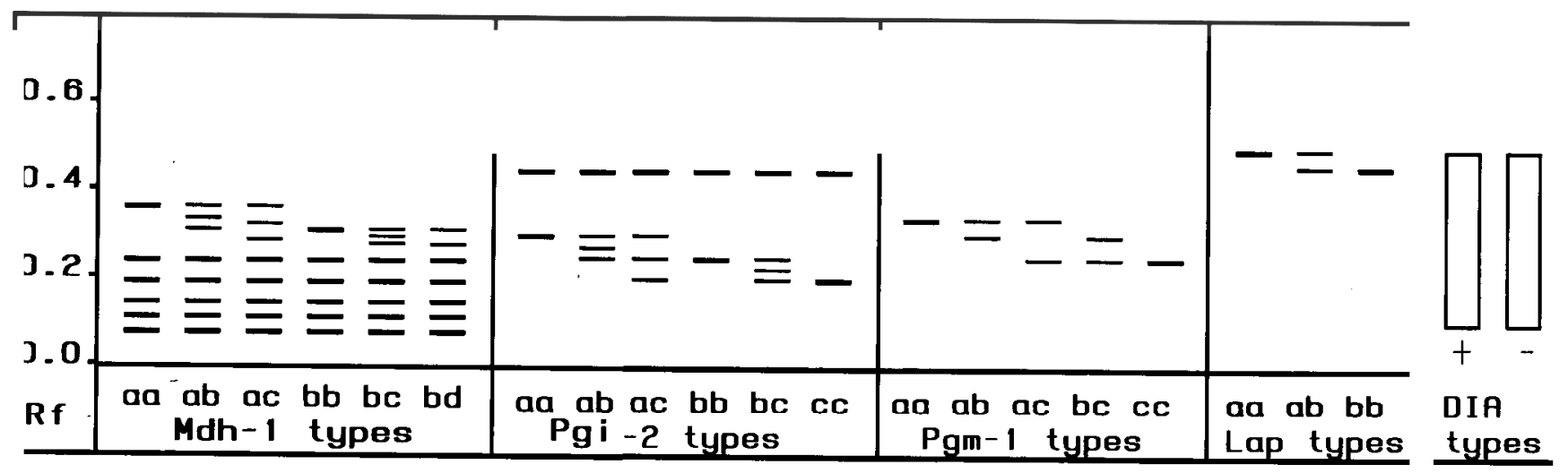

Fig. 3. Diagrammatic representation of banding patterns and genotypes observed in pecan for malate dehydrogenase $(M d h-1)$, phosphoglucose isomerase (Pgi-2), phosphoglucomutase (Pgm-1), leucine aminopeptidase (Lap-1), and diaphorase (DIA). The open rectangle for DIA represents a region where a complex of DIA isozymes are produced.

Table 1. Parental genotypes of crosses made, segregation of progeny, chi-square statistic, and probability for simple inheritance of leucine aminopeptidase (Lap-1) in pecan.

\begin{tabular}{|c|c|c|c|c|c|c|c|}
\hline \multirow{2}{*}{$\begin{array}{l}\text { Parental } \\
\text { genotypes }\end{array}$} & \multicolumn{3}{|c|}{ Progeny types } & \multirow{2}{*}{$\begin{array}{c}\text { Total } \\
\text { progeny }\end{array}$} & \multirow{2}{*}{$\begin{array}{l}\text { Test } \\
\text { ratio } \\
\end{array}$} & \multirow[b]{2}{*}{$\chi^{2}$} & \multirow{2}{*}{$\begin{array}{c}\text { Probability } \\
(\%) \\
\end{array}$} \\
\hline & $a a$ & $a b$ & $b b$ & & & & \\
\hline$a a \times a a$ & 40 & --- & --- & 40 & --- & -- & --- \\
\hline$a a \times a b$ & 17 & 15 & --- & 32 & $1: 1$ & 0.13 & $50-75$ \\
\hline$a b \times a a$ & 9 & 16 & --- & 25 & $1: 1$ & 1.96 & $10-25$ \\
\hline$a b \times a b$ & 36 & 72 & 34 & 142 & $1: 2: 1$ & 0.08 & $95-97$ \\
\hline$a b \times b b$ & --- & 9 & 20 & 29 & $1: 1$ & 4.17 & $2.5-5$ \\
\hline
\end{tabular}




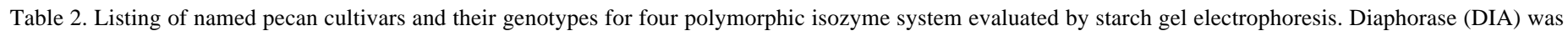

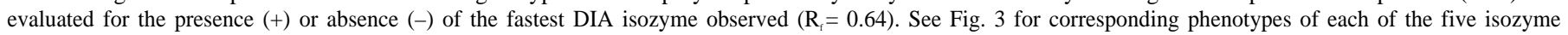
systems.

\begin{tabular}{|c|c|c|c|c|c|c|c|}
\hline \multirow[b]{2}{*}{ Cultivar } & \multirow[b]{2}{*}{ Location $^{\mathrm{z}}$} & \multicolumn{5}{|c|}{ Enzyme } & \multirow{2}{*}{$\begin{array}{r}\text { Isozyme } \\
\text { class }^{y}\end{array}$} \\
\hline & & $P g m-1$ & $P g i-2$ & $M d h-1$ & Lap-1 & DIA & \\
\hline Grotian, Donald & B-142-23 & $\mathrm{aa}^{-}$ & aa & aa & $\mathrm{bb}$ & + & 1 \\
\hline Major & B-52-24C & aa & aa & aa & bb & + & 1 \\
\hline Mount & B-125-21 & aa & aà & aa & $\mathrm{bb}$ & + & 1 \\
\hline Mrs James Spence & B-142-25 & aa & aa & aa & $\mathrm{bb}$ & + & 1 \\
\hline Ideal & B-64-25 & aa & aa & aa & $b b$ & - & 2 \\
\hline McNeil & B-116-27 & aa & aa & aa & bb & - & 2 \\
\hline Osage & B-121-33.5 & aa & aa & aa & bb & - & 2 \\
\hline San Saba & B-119-18 & aa & aa & aa & $\mathrm{bb}$ & - & 2 \\
\hline Hayes & B-103-28 & aa & aa & aa & $a b$ & - & 3 \\
\hline Risien \#1 & B-38-26 & aa & aa & aa & $a b$ & - & 3 \\
\hline Seminole & B-106-23 & aa & aa & aa & $a b$ & - & 3 \\
\hline Wallops Island & B-133-40 & aa & aa & aa & $a b$ & - & 3 \\
\hline R-5010 & B-115-26 & aa & aa & aa & $a b$ & - & 3 \\
\hline Pointe Coupee $\# 2^{x}$ & B-134.5-47.5 & aa & aa & $\mathrm{bb}$ & aa & - & 4 \\
\hline Aggie & B-104-30 & aa & aa & bb & $\mathrm{bb}$ & - & 5 \\
\hline Carmichael & $\mathrm{B}-40-24$ & aa & aa & $\mathrm{bb}$ & $\mathrm{bb}$ & - & 5 \\
\hline Kuykendall & $B-40-27$ & aa & aa & $\mathrm{bb}$ & bb & - & 5 \\
\hline Coy & B-52-24 & aa & aa & $\mathrm{bb}$ & $a b$ & - & 6 \\
\hline Golden & B-110-31 & aa & aa & $\mathrm{bb}$ & $a b$ & - & 6 \\
\hline Oconee & B-132-23 & aa & aa & bb & $a b$ & - & 6 \\
\hline Schley & B- $40-5$ & aa & aa & $\mathrm{bb}$ & $a b$ & - & 6 \\
\hline Sioux & $B-47-23$ & aa & aa & $\mathrm{bb}$ & $a b$ & - & 6 \\
\hline Hollis $^{x}$ & B-131-17 & aa & aa & $a b$ & $\mathrm{bb}$ & + & 7 \\
\hline VC-168 & SVR-3-4 & aa & aa & $a b$ & $\mathrm{bb}$ & - & 8 \\
\hline Hodge & B-110-18 & aa & aa & $a b$ & $\mathrm{bb}$ & - & 8 \\
\hline Onliwon & $B-41-25$ & aa & aa & $a b$ & $\mathrm{bb}$ & - & 8 \\
\hline Roth & $B-44-25$ & aa & aa & $a b$ & $\mathrm{bb}$ & - & 8 \\
\hline San Saba Imp. & B- $42-0$ & aa & aa & $a b$ & $\mathrm{bb}$ & - & 8 \\
\hline Shawnee & B-6-16 & aa & aa & $a b$ & $\mathrm{bb}$ & - & 8 \\
\hline Sovereign & B-118-18 & aa & aa & $a b$ & bb & - & 8 \\
\hline Van Deman & NGR-1-28 & aa & aa & $a b$ & bb & - & 8 \\
\hline $\operatorname{Tejas}^{\mathrm{x}}$ & B-138-23 & aa & aa & $a b$ & $a b$ & + & 9 \\
\hline Caddo & B-138-27 & aa & aa & $a b$ & $a b$ & - & 10 \\
\hline Sumner & SVR 18-4 & aa & aa & $a b$ & ab & - & 10 \\
\hline Chief $^{x}$ & B-104-21 & aa & aa & ac & ab & - & 11 \\
\hline Nugget $^{x}$ & B-61-24 & aa & aa & bd & $\mathrm{bb}$ & - & 12 \\
\hline Sullivan $^{x}$ & B-102-22 & aa & aa & bd & $a b$ & - & 13 \\
\hline Frotscher & G-2-4 & aa & $\mathrm{bb}$ & aa & $\mathrm{bb}$ & + & 14 \\
\hline Pawnee & B-133-37 & aa & $\mathrm{bb}$ & aa & $\mathrm{bb}$ & + & 14 \\
\hline Super Stuart & B-105-16 & aa & $\mathrm{bb}$ & aa & $\mathrm{bb}$ & + & 14 \\
\hline Devore & B-117-27 & aa & bb & aa & $\mathrm{bb}$ & - & 15 \\
\hline Dooley & B-103-15 & aa & bb & aa & bb & - & 15 \\
\hline Humble & B- $-41-24$ & aa & $\mathrm{bb}$ & aa & $\mathrm{bb}$ & - & 15 \\
\hline Oakla & B-125-18 & aa & $\mathrm{bb}$ & aa & bb & - & 15 \\
\hline Pabst & NGR-2-30 & aa & $\mathrm{bb}$ & aa & bb & - & 15 \\
\hline Starking Hardy Giant ${ }^{\mathrm{x}}$ & B-103-31 & aa & $\mathrm{bb}$ & aa & $a b$ & + & 16 \\
\hline Jack Doby ${ }^{x}$ & B-133-43.5 & aa & $\mathrm{bb}$ & $\mathrm{bb}$ & $b b$ & + & 17 \\
\hline Cheyenne & B-145-22 & aa & $\mathrm{bb}$ & $\mathrm{bb}$ & $b b$ & - & 18 \\
\hline GraKing & B-133-48.5 & aa & $\mathrm{bb}$ & $\mathrm{bb}$ & $\mathrm{bb}$ & - & 18 \\
\hline Melrose & B-103-17 & aa & $\mathrm{bb}$ & $\mathrm{bb}$ & $\mathrm{bb}$ & - & 18 \\
\hline Meyers (TX) & B-50-24 & aa & $\mathrm{bb}$ & $\mathrm{bb}$ & bb & - & 18 \\
\hline Odom & B-53-24 & aa & $\mathrm{bb}$ & $\mathrm{bb}$ & $\mathrm{bb}$ & - & 18 \\
\hline Candy $^{x}$ & B-134.5-46.5 & aa & bb & bb & $a b$ & + & 19 \\
\hline Keilers ${ }^{x}$ & B-119-22 & aa & $\mathrm{bb}$ & $\mathrm{bb}$ & $a b$ & - & 20 \\
\hline Mohawk & B-139-27 & aa & $\mathrm{bb}$ & $a b$ & bb & + & 21 \\
\hline Plainsman & B-109-18 & aa & $\mathrm{bb}$ & $a b$ & bb & + & 21 \\
\hline Bill Nut & B-102-19 & aa & $\mathrm{bb}$ & $a b$ & bb & - & 22 \\
\hline Comanche & B-145-18 & aa & $\mathrm{bb}$ & $a b$ & bb & - & 22 \\
\hline Dependable & SVR-8-3 & aa & $\mathrm{bb}$ & $a b$ & bb & - & 22 \\
\hline GraZona & B-139-20 & aa & $\mathrm{bb}$ & $a b$ & bb & - & 22 \\
\hline Hilton & B-104-25 & aa & $\mathrm{bb}$ & $a b$ & $b b$ & - & 22 \\
\hline Hirschi & B-149-39.5 & aa & $\mathrm{bb}$ & $a b$ & $\mathrm{bb}$ & - & 22 \\
\hline Jersey & B- $39-25$ & aa & $\mathrm{bb}$ & $a b$ & $\mathrm{bb}$ & - & 22 \\
\hline
\end{tabular}


Table 2. Continued.

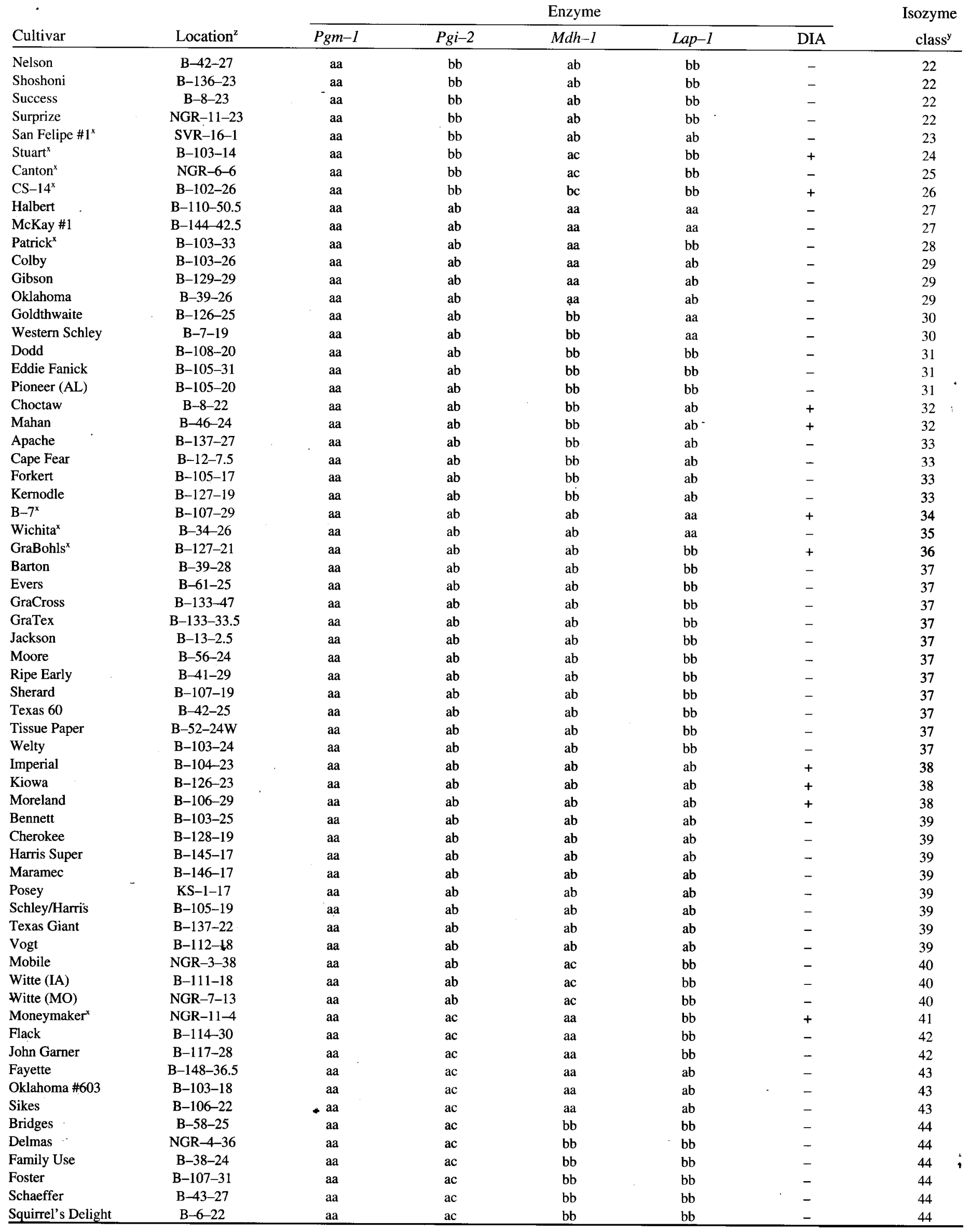


Table 2. Continued.

\begin{tabular}{|c|c|c|c|c|c|c|c|}
\hline \multirow[b]{2}{*}{ Cultivar } & \multirow[b]{2}{*}{ Location $^{2}$} & \multicolumn{5}{|c|}{ Enzyme } & \multirow{2}{*}{$\begin{array}{r}\text { Isozyme } \\
\text { class }^{y}\end{array}$} \\
\hline & & $P g m-1$ & $P g i-2$ & $M d h-1$ & $L a p-1$ & DIA & \\
\hline Wright & B-105-22 & aa & ac & $\mathrm{bb}$ & bb & - & 44 \\
\hline Bon Chance $^{x}$ & B-105-33 & aa & $\mathrm{ac}$ & $\mathrm{bb}$ & $a b$ & - & 45 \\
\hline $\operatorname{Red}^{x}$ & B-144-20 & aa & $\mathrm{ac}$ & $a b$ & aa & - & 46 \\
\hline Teche $^{x}$ & NGR-2-42 & aa & $\mathrm{ac}$ & $a b$ & bb & - & 47 \\
\hline Best's Early & B-128-29 & aa & $\mathrm{ac}$ & ab & $a b$ & - & 48 \\
\hline Brooks & B-114-29 & aa & $\mathrm{ac}$ & $a b$ & $a b$ & - & 48 \\
\hline Gormely & B-126-18 & aa & $\mathrm{ac}$ & $a b$ & $a b$ & - & 48 \\
\hline Owens & B-145-23 & aa & $\mathrm{ac}$ & $a b$ & $a b$ & - & 48 \\
\hline Nellis & B-133-31.5 & aa & ac & bc & $\mathrm{bb}$ & - & 49 \\
\hline Woodroof & NGR-1-33 & aa & $\mathrm{ac}$ & $\mathrm{bc}$ & bb & - & 49 \\
\hline Gloria Grande $^{\mathrm{x}}$ & B-44-26 & aa & $b c$ & aa & $\mathrm{bb}$ & + & 50 \\
\hline Jennings & B-102-30 & aa & $\mathrm{bc}$ & aa & bb & - & 51 \\
\hline Limpia Creek\#1 & NGR & aa & $\mathrm{bc}$ & aa & $\mathrm{bb}$ & - & 51 \\
\hline Louella Lewis & B-103-23 & aa & $\mathrm{bc}$ & aa & $\mathrm{bb}$ & - & 51 \\
\hline McCulley & B-133-47.5 & aa & $\mathrm{bc}$ & aa & $\mathrm{bb}$ & - & 51 \\
\hline Schneider & B-111-17 & aa & $\mathrm{bc}$ & aa & $\mathrm{bb}$ & - & 51 \\
\hline Johnson $(\mathrm{KS})^{\mathrm{x}}$ & B- $-40-30$ & aa & $\mathrm{bc}$ & aa & $a b$ & - & 52 \\
\hline Cherry Creek \#1 & NGR & aa & bc & bb & $\mathrm{bb}$ & - & 53 \\
\hline Oklahoma \#601 & B-105-30 & aa & bc & bb & $b b$ & - & 53 \\
\hline Waukeenah & NGR-1-31 & aa & bc & bb & bb & - & 53 \\
\hline Burkett & B-1-16 & aa & bc & $a b$ & bb & - & 54 \\
\hline Chickasaw & B-130-23 & aa & bc & $a b$ & bb & - & 54 \\
\hline Farley & B-107-25 & aa & $\mathrm{bc}$ & $\mathrm{ab}$ & bb & - & 54 \\
\hline Giles & B-102-14 & aa & $\mathrm{bc}$ & $\mathrm{ab}$ & $\mathrm{bb}$ & - & 54 \\
\hline Mayo & B-103-35 & aa & $\mathrm{bc}$ & $a b$ & bb & - & 54 \\
\hline Merket & B-110-19 & aa & bc & $a b$ & $\mathrm{bb}$ & - & 54 \\
\hline Russell & B-57-24 & aa & bc & $a b$ & bb & - & 54 \\
\hline Woodard & B-135-30 & aa & bc & $a b$ & $\mathrm{bb}$ & - & 54 \\
\hline Cowley $^{x}$ & B-124-18 & aa & bc & $a b$ & $a b$ & + & 55 \\
\hline Jack Ballard ${ }^{x}$ & B-105-23 & aa & bc & ac & bb & + & 56 \\
\hline Greenriver $^{x}$ & B-110-16 & aa & $\mathrm{cc}$ & aa & bb & - & 57 \\
\hline Kibler $^{x}$ & B-109-28 & $a b$ & aa & aa & bb & - & 58 \\
\hline Elliott $^{\mathrm{x}}$ & B $-42-28$ & $a b$ & aa & $a b$ & $a b$ & - & 59 \\
\hline Hastings $^{x}$ & B-108-29 & $a b$ & $a b$ & bb & $b b$ & - & 60 \\
\hline Houmax $^{x}$ & B-135-23 & $a b$ & $a b$ & bb & $a b$ & - & 61 \\
\hline$A-93^{x}$ & B-108-31 & $a b$ & $a b$ & $a b$ & bb & - & 62 \\
\hline Ranger ${ }^{x}$ & B-142-18 & $\mathrm{ac}$ & aa & $a b$ & aa & - & 63 \\
\hline Peruque $^{\mathrm{x}}$ & B-103-30 & ac & $\mathrm{bb}$ & aa & bb & - & 64 \\
\hline Freeman ${ }^{x}$ & B-39-24 & ac & $b b$ & $a b$ & bb & - & 65 \\
\hline Brake $^{x}$ & B-63-24 & ac & $a b$ & aa & bb & - & 66 \\
\hline Osborne $^{x}$ & B-59-24 & $\mathrm{ac}$ & $a b$ & $a b$ & $b b$ & - & 67 \\
\hline Bradley (FL) & B-105-18 & $\mathrm{ac}$ & $a b$ & $a b$ & $a b$ & - & 68 \\
\hline Riverside & B-127.5-39 & $\mathrm{ac}$ & $a b$ & $a b$ & $a b$ & - & 68 \\
\hline Centennial & B-112-20 & ac & $\mathrm{ac}$ & $a b$ & $a b$ & - & 69 \\
\hline Jerome & B-117-19 & $\mathrm{ac}$ & $\mathrm{ac}$ & $a b$ & $a b$ & - & 69 \\
\hline Seguin & B-104-31 & $\mathrm{ac}$ & $\mathrm{ac}$ & $a b$ & $a b$ & - & 69 \\
\hline Willmann ${ }^{\mathrm{x}}$ & B-102-20 & $\mathrm{ac}$ & $\mathrm{bc}$ & $a b$ & bb & + & 70 \\
\hline Alley $^{x}$ & NGR-4-28 & $\mathrm{ac}$ & $\mathrm{bc}$ & $a b$ & bb & - & 71 \\
\hline Curtis $^{x}$ & B-102-33 & $b c$ & $a b$ & $a b$ & aa & - & 72 \\
\hline
\end{tabular}

B = USDA-ARS Poage Pecan Breeding Station; Brownwood, Texas; NGR = USDA-ARS National germplasm repository, Brownwood; SVR = Somerville repository, Somerville, Texas. Numbers following the prefix correspond to row and column position of each individual in the plantation.

'Cultivars with a similiar isozyme class number exhibit the same five isozyme banding patterns.

${ }^{x}$ Cultivars that possess a unique combination of isozyme phenotypes.

Pgm-1, and Lap-1 (Fig. 3). The genetic control of these first three genes has been reported (Marquard 1987, 1991).

The faster polymorphic region of LAP (designated Lap-1) appears to be simply inherited with codominant expression by alleles. The observed segregation generally conforms to the expected ratios for a simply inherited model (Table 1). However, progeny from an $a b$ by $b b$ cross showed a significant deviation from the expected segregation ratio, which remains unexplained. The single-banded phenotypes are most likely homozygous for
Lap-1 and are arbitrarily assigned genotypes of $a a$ and $b b$ (Fig. 3). The double-banded phenotype, therefore, is heterozygous with an $a b$ genotype. LAP in pecan appears monomeric given the doublebanded phenotype of the heterozygote of Lap-1.

More than 170 pecan cultivars were genotyped for Pgm-1, Pgi2, Mdh-1, and Lap-1 and were scored for the presence (+) or absence (-) of a single fast DIA band (Table 2). Cultivars were sorted by common banding patterns using these five isozyme systems. Cultivars that shared identical isozyme patterns were 
grouped together into isozyme classes.

The ability to differentiate among cultivars by isozymes was good. The 177 cultivars sorted into 72 classes (Table 2). Forty of the cultivars $(23 \%)$ possessed a unique series of isozyme patterns. Most cultivars (124 of 177) shared common banding patterns with less than four other cultivars (Table 2).

Several cultivars were previously characterized by isozymes and are inconsistent with work reported herein. 'Brake', 'Elliott', 'Moore', 'Schley', and 'Stuart' were initially assigned an incorrect genotype for Pgm-1, Mdh-1, or Pgi-2 (Marquard, 1987, 1991). Presumably, some tissue collected for earlier analyzes include samples that were not true-to-type or from specimens that had not been successfully grafted. Trees sampled for this study have been vouchered to reduce the likelihood of sampling error.

Allelic frequencies were calculated for the four loci. Pgm-1 and $M d h-1$ each had two alleles that were uncommon among the cultivars with a frequency of $<5 \%$. Pgm- 1 had three alleles $(a, b$, and c) with allelic frequencies of $94.6 \%, 1.7 \%$, and $3.7 \%$, respectively. Alleles $a, b$, and $c$ for Pgi-2, had allelic frequencies of $44.6 \%, 41.5 \%$, and $13.8 \%$, respectively. $M d h-1$ has four alleles ( $a$, $b, c$, and $d$ ) with frequencies of $49.7 \%, 46.9 \%, 2.8 \%$, and $0.6 \%$, respectively. Alleles of Lap-1 ( $a$ and $b$ ) had a frequency of $21.8 \%$ and $78.2 \%$; respectively. Heterodichogamy patterns, as reported by Thompson and Young (1985), were not related to the observed genotypes nor to the presence of a fast DIA band.

The genotypic data presented has historical significance in substantiating parentage of several cultivars (Table 2). For example, E.E. Risien of San Saba County, Texas, named many cultivars in the early 1900s. Most Risien cultivars are thought to be progeny of his 'San Saba' selection. 'Western Schley' is the second most common cultivar in pecan orchards today (Thompson, 1990), and is thought to be a seedling from 'San Saba' (see Thompson and Young, 1985). However, given the genotypes of Mdh-1 and Lap-1, 'San Saba' [aa:bb for Mdh-1:Lap-1] could not have parented 'Western Schley' [bb:aa for Mdh-1:Lap-1] (Table 2). Similiarly, the $M d h-1$ genotype for 'San Saba' [au] is inconsistent as a parent of 'Squirrel's Delight' $[b b]$. From Pgi-2, 'John Garner' with art [at] genotype could not have been parented by 'San Saba Improved' [au] x 'Onliwon' [au].

Isozyme analyses in pecans can now be used to help substantiate parentage, verify cultivars, and estimate self-pollination rates (Marquard, 1988; Wood and Marquard, 1992). Cultivars possessing low-frequency alleles (ie., $<5 \%$ ) would be useful in studies of gene flow and reproductive biology. 'Curtis' would be a particu- larly useful pollen parent in reproductive studies in that it contains a pair of unusual alleles [bc] for Pgm-1 (Table 2). 'Riverside', 'Peruque' 'Stuart', 'Nugget', 'Sullivan', and other cultivars contain at least one unusual allele (Table 2) and would also be a good choice for a pollen parent.

Four isozyme systems are now documented to be simply inherited in pecan and diaphorase can serve as a biochemical marker to help verify cultivar identity. The ability to differentiate among cultivars is good and isozymes can help substantiate pedigrees.

\section{Literature Cited}

Little, Jr., E.L. 1971. Atlas of United States trees. vol. 1. Important eastern hardwoods. U.S. Dept. of Agr. For. Serv. Misc. Publ. 1146.

Marquard, R.D. 1987. Isozyme inheritance, polymorphism, and stability of malate dehydrogenase and phosphoglucose isomerase in pecan. $\mathrm{J}$ Amer. Soc. Hort. Sci. 112:717-721.

Marquard, R.D. 1988. Outcrossing rates in pecan and the potential for increased yields. J. Amer. Soc Hort. Sci. 112:84-88.

Marquard, R.D. 1989. Rare allozymes of malate dehydrogenase in pecan. HortScience 24:156.

Marquard, R.D. 1991. Inheritance of phosphoglucomutase isozymes in pecan. HortScience 26:1213-1214.

Marquard, R.D. and R.G. Skorpenske. 1989. Expression of heritable biochemical markers from various pecan tissues. Euphytica 42:65-70.

Peirce, L.C. and J.L. Brewbaker. 1973. Applications of isozyme analysis in horticultural science. HortScience 8: 17-22.

Shields, C. R., T.J. Orton, and C.W. Stuber. 1983. An outline of general resource needs and procedures for the electrophoretic separation of active enzymes from plant tissues, p. 443468. In: S.D. Tanksley and T.J. Orton (eds.). Isozymes in plant genetics and breeding. Part A. Elsevier, Amsterdam

Thompson, T.E. 1990. Update pecan cultivars: Current use and recommendations. Pecan South 24: 12-20.

Thompson, T.E. and L.J. Grauke. 1990. Pecans and hickories (Carya). Acta Hort. 290: 839-904.

Thompson, T.E. and F. Young. 1985. Pecan cultivars-Past and present. Texas Pecan Growers Assn., College Station.

Vallejos, C.E. 1983. Enzyme activity staining, p. 469-516. In: S.D. Tanksley and T.J. Orton (eds.). Isozymes in plant genetics and breeding. Part A. Elsevier, Amsterdam

Wendel, J.F. and C.R. Parks. 1982. Genetic control of isozyme variation in Camellia japonica L. J. Hered. 73: 197-204.

White, GA., H.L. Shands, and G.R. Lovell. 1989. History and operation of the national germplasm system. Plant Breeding Rev. 7: 1-56.

Wood, B.W. and R.D. Marquard. 1992. Estimates of self-pollination in pecan orchards in the southeastern United States. HortScience 27:406-408. 